\title{
Value Creation and Power Asymmetries in Digital Ecosystems: A Study of a Cloud Gaming Provider
}

\author{
Arto Ojala, Nina Helander, and Pasi Tyrväinen
}

Abstract Digital platforms connecting users and service providers have a central role in determining the value creation structure of ecosystems. Platform developers try to achieve a dominant position for the platform with a strong ecosystem around it. The size and attractiveness of the services can attract new users, and growing user volume can bring new co-operative service providers to the service partner network. An interesting question is how the presence of power and potential power asymmetry affect the value

\footnotetext{
A. Ojala $(\bowtie)$

School of Marketing and Communication, University of Vaasa, Vaasa, Finland e-mail: arto.ojala@univaasa.fi

N. Helander

Faculty of Management and Business, Tampere University, Tampere, Finland e-mail: nina.helander@tuni.fi

P. Tyrväinen

Faculty of Information Technology, University of Jyväskylä, Jyväskylä, Finland e-mail: pasi.tyrvainen@jyu.fi

(C) The Author(s) 2020

T. Lynn et al. (eds.), Measuring the Business Value of Cloud

Computing, Palgrave Studies in Digital Business \& Enabling

Technologies, https://doi.org/10.1007/978-3-030-43198-3_6
} 
creation capability and the structure of a network around a platform? This chapter describes an example of value creation and the influence of power asymmetry in a digital ecosystem built around a cloud gaming platform.

Keywords Digital ecosystems • Digitalisation • Digital platforms • Partner networks

\subsection{INTRODUCTION}

The digitalisation of artifacts provides new opportunities that change traditional business models and how services are delivered to end-users (Baber et al. 2019; Ojala 2016; Yoo et al. 2010). In particular, digital platforms that enable emergence of new kinds of ecosystems are changing the way people interact with digital technology (Adner 2012; Yoo 2010). These ecosystems can be conceptualised as "a loosely coupled network of actors who interact and offer resources of different kinds, which together form a digital service around the platform" (Ojala et al. 2018, p. 729). In ecosystems, digital platforms have a central role that determines the structure of the ecosystem. Achieving a dominant position for a platform and building a strong ecosystem around the platform is a demanding process in which value creation has a central role.

Compared to the traditional value creation chains where value moves from a firm to customers (Porter 1985), digital platform providers must consider how value is generated for multiple sides of the platform (Eisenmann et al. 2006). Furthermore, actors on the different sides of the platform depend on the size and attractiveness of the other side of the market (Adner 2012). For instance, in the videogame industry where competition among various gaming platforms is intense (Lee 2012), game studios are more likely to develop games for platforms that have a lot of existing players. In line, video game players tend to favour gaming platforms that provide a high volume of interesting game content. Developing a platform that provides value to multisided markets and building a strong ecosystem is a complex and demanding process (Ojala and Lyytinen 2018). Even if a firm has an excellent innovation for a gaming platform, the firm's value creation still largely relies on other innovations within the ecosystem (Adner 2012; Lee 2012) and the power the firm has over other firms.

To better understand value creation and the concept of power in digital ecosystems, this chapter examines the value creation literature (Allee 
2000) and management studies on organisational power (Astley and Sachdeva 1984; Mintzberg 1978). Specifically, we contribute to understanding of this topic in the context of digital platforms by studying ( 1 ) what kind of direct and indirect value is generated in the focal partner network, (2) how the focal network and the power positions evolve over time, and (3) how power asymmetry influences value creation within the network. We focus on the videogame industry because it has multisided markets, and ecosystems have a strong role (Lee 2012; McIntyre and Srinivasan 2017). Further, the industry has a relatively long history with well-established gaming platforms (Lee 2012). This makes the entry of newcomers challenging as they may have very little power in the market, and they have to create new ecosystems from scratch (Ojala 2016).

\subsection{Digital Platforms and Ecosystems}

Digital platforms are generally organised in a network-like architecture, referred to as a layered modular structure with loosely coupled interfaces (Yoo et al. 2010). The architecture forms a hybrid of a modular structure and a layered structure (cf. Ulrich 1995). The architecture emerges when digital components and functions form the primary platform services or when the components and functions are embedded in hierarchically organised product structures (Yoo et al. 2010). In the loosely coupled, multi-layered architecture, the digital platform is organised in four layers: (1) device, (2) network, (3) service, and (4) content. The device layer refers to physical devices that connect and interact with the platform and its services, such as a television set, a mobile phone, or a gaming console. The network layer refers to the networking protocols that the platform offers to communicate over the networks to devices at the device layer. The service layer relates to the functionality of the applications that run on the platform and that enable users to use the content across different devices. The content layer covers the content that customers interact with, such as music, games, or videos. These layers form an ecosystem around the digital platform where several diverse actors, such as platform owners, content providers, telecom operators, device manufacturers, end-users, etc. (Koch and Windsperger 2017; Tiwana 2013), may participate, create value, and form multisided markets (Eisenmann et al. 2006). All these actors shape the competition and power asymmetries around the digital platform because each actor has unique interests and motivations for participating in the ecosystem. 


\subsection{Value Creation Within Digital Ecosystems}

In this chapter, we use term "partner network" to refer to various actors within the ecosystem that cooperate directly with the focal firm. To operate successfully in the ecosystem, a firm must recognise the potential and current actors in the ecosystem that contains the firm's partner network (Ojala and Helander 2014). Thus, a partner network is a more focused part of the larger digital network. In the platform context, the network has the characteristics of the triangular structure typical of two-sided markets (Eisenmann et al. 2006). These partners can usually be grouped into producers and customers, and in the gaming industry, into game developers and consumers. Between these two main actor groups, the platform provider as the focal firm acts as an intermediary for creating value. Further, the focal firm needs to identify the value of their own offering, and how this value can be delivered to benefit other actors in the network. Thus, a firm should map all the actors in the ecosystem that could benefit from the firm's offering and the resources that the firm will need to commercialise their service (Allee 2000).

Created value can be defined as a trade-off between benefits and sacrifices (Lapierre 2000) that can be monetary or non-monetary. Monetary benefits and costs are usually easier to measure. However, the role of nonmonetary rewards and costs in value perception is significant, too. Nonmonetary rewards can be a status reward, emotional reward, or gain of new competences, while non-monetary costs may include the time, effort, energy, and amount of conflict customers engage in to obtain the product or service (Walter et al. 2001).

Value creation from a functional perspective (Walter et al. 2001) offers a view on the types of activities that actors may perform to create more value for network members. According to function-oriented value analysis, a firm may gain value from relationships with direct and indirect functions. Direct value can be produced through profit, volume, and safeguard functions. (Walter et al. 2001). For example, a safeguard function is a direct value creation function: If the firm has a long contract with the customer, this relationship creates safeguard value for the firm. Indirect functions, in contrast, require the input of third parties. Indirect functions include market, access, and innovation functions. For example, the market function means that one actor gives access to another market area with new potential partner actors. 


\subsection{The Concept of Power in Partner Networks}

Astley and Sachdeva (1984) identified three sources of power: hierarchical authority, resource control, and network centrality. Hierarchical authority often relates to official positions that actors have over one another, so they are usually coupled with actors like authorities or supervisors (Astley and Sachdeva 1984). Resource control looks at the environment of an organisation, as it states that everyone is dependent on the resources of others: "organizations are open social systems that require a supply of resources from the environment in order to sustain their operations" (Astley and Sachdeva 1984, p. 106). Thus, no organisation or actor can act alone. Power based on resources is naturally higher in the case of critical or hardto-obtain resources than in bulk resources. The third source of power, network centrality, refers to the position of an actor in a network (Easton 1992). Håkansson and Snehota (1989) argued that network actors aim to increase their own power and influence in networks as the actors believe that more powerful positions within a network will enable the actors to achieve other objectives. An actor's power and position within a network are closely related. In the end, power is realised in the interaction processes that form a relationship (Turnbull and Valla 1986); there cannot be power without the other part of the relationship.

\subsection{Research Method}

This chapter examines a qualitative, longitudinal case. A case study provides detailed (Edmondson and Mcmanus 2007) and empirically rich data (Eisenhardt and Graebner 2007) connected to a complex phenomenon. A longitudinal case study also facilitates examination of the evolution of a firm's activities (Eisenhardt 1989) and partner networks (Ford and Redwood 2005). In the data collection, we combined interview and secondary material covering the whole history of the firm from 2000 to 2015. We conducted 15 interviews, each lasting 45-90 minutes. Secondary data sources included the firm's brochures and press releases, which provided an extensive and detailed historical description of the firm. By using this information, we also triangulated the information. In the data analysis, we followed the steps: (1) data condensation, (2) data display, and (3) drawing and verifying conclusions as recommended by Miles and Huberman (1994). 


\subsection{G-CLuster}

The case firm, G-cluster, develops games-on-demand services. Throughout the history, G-cluster has been small, employing 10-40 persons. Compared to traditional videogame platform providers (see Lee 2012), G-cluster's business idea is based on a completely different way of providing videogames to players. Traditionally, games are installed on a computer or a game console that runs the game. In the G-cluster business model, games are run on the platform operated by telecom operators on their game servers. The game server transmits the game content to the end users' devices over the broadband network. The client devices receive the stream, display the game, and transmit users' commands back to the game server. Thus, G-cluster's gaming platform makes it possible to bring games to the cloud environment. The commercialisation has been challenging as the industry is dominated by large and well-known gaming platform providers making market entry for newcomers difficult. However, as G-cluster was the first cloud-based gaming platform provider in the market, the firm's innovation attracted increasing interest among potential partners.

\subsubsection{Creation of a Partner Network}

G-cluster's business goal was new in 2000 and took time to evolve, thus the first real partner network emerged in 2005 (Fig. 6.1). The figure shows the key partners within the ecosystem that G-cluster acted with directly (straight arrow) when the firm commercialised its service. First, G-cluster needed content for the gaming platform. To acquire game content, which was critical for G-cluster's service, the firm partnered with game publishers and licensed games for the platform on a revenuesharing basis.

Revenue sharing gave G-cluster access to a portfolio of games while protecting the firm's cash flow. However, the potential revenue was not, in many cases, appealing as a primary partnering factor for the game publishers. As a result, G-cluster had to demonstrate other benefits-benefits that would bring value to the game publishers - if they provided games for the platform (see also Ojala and Tyrväinen $2011 \mathrm{a}, \mathrm{b}$ ). G-cluster motivated game studios by emphasising the benefits of cloud computing, like avoiding piracy, illegal copying, and second-hand markets for the games.

G-cluster also needed partners that are capable of running their cloud gaming service on their servers and provide access for players to services. 


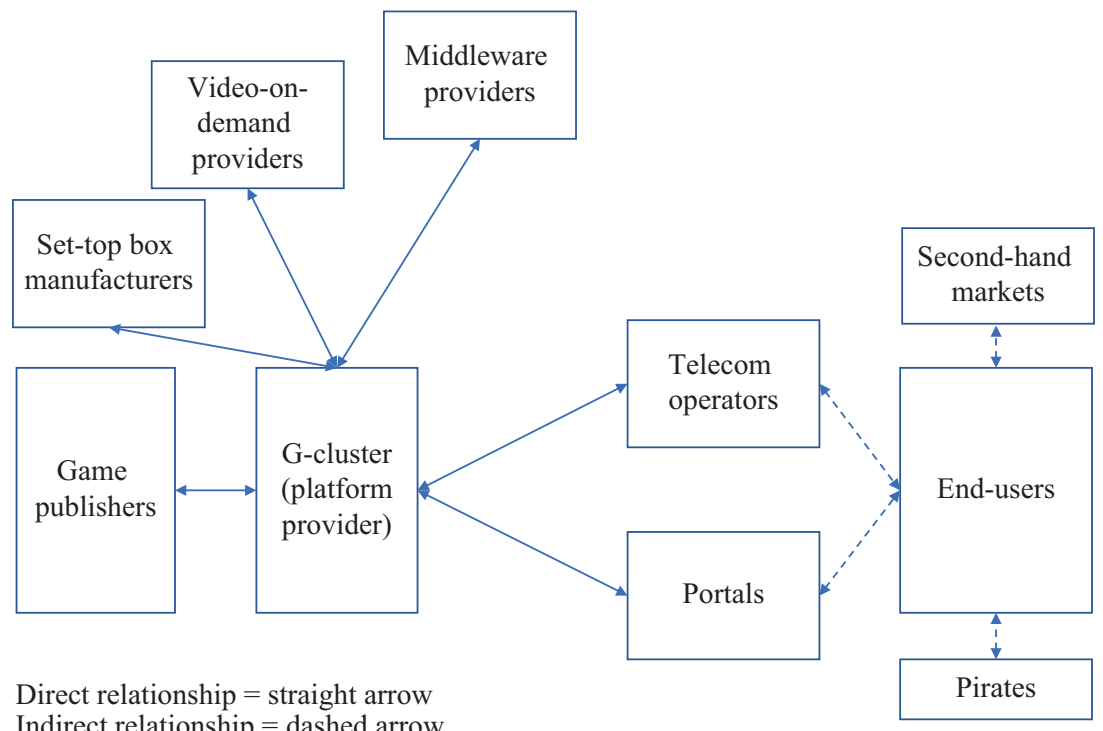

Indirect relationship $=$ dashed arrow

Fig. 6.1 The partner network in 2005

Consequently, G-cluster developed relationships with telecom operators that became important partners within the ecosystem. Telecom operators had good marketing channels and a large, existing customer base. As they are big players in the market, they also offered more visibility and a brand name that could be used for marketing purposes. Operators also motivated game studios to make their games available on G-cluster's platform. However, the move toward cooperation with telecom operators was not easy due to their powerful market position. G-cluster needed to demonstrate the value of their product for telecom operators. In addition to monetary benefits, G-cluster's service offered a good opportunity to extend the telecom operators' existing product portfolio and differentiate their offering from that of competitors.

To commercialise the service and to partner with telecom operators, G-cluster needed resources from video-on-demand service providers, settop box manufacturers, and middleware software providers. For video-ondemand service providers, G-cluster's game platform offered new functionalities and enabled them to offer more content for telecom operators. Set-top box manufacturers needed new functions for their devices, 
and G-cluster's gaming platform brought extra value. Middleware software providers, which sell software to telecom operators, benefited from G-cluster's platform, as they were able to integrate game-on-demand services in the telecom operators' set-top boxes. The cooperation among these three different types of firms was based mainly on the mutual benefits that the partner network provided rather than on monetary benefits. These relationships were symmetric in the power aspect.

Portals (like Yahoo) were also important partners within the partner network that gave PC users access to G-cluster's cloud gaming service, and enabled multihoming of the service. The portals also took care of marketing activities and charged customers via the portals' invoicing systems. For the portals, G-cluster's cloud service generated revenue without requiring any investment, and the service was easily integrated with their current business.

\subsubsection{Evolution in Partner Networks}

Over a five-year period, changes in the ecosystem, markets and G-cluster's services impacted the partner network (Fig. 6.2). Due to the increasing competition in the PC game markets and the emergence of free-to-play

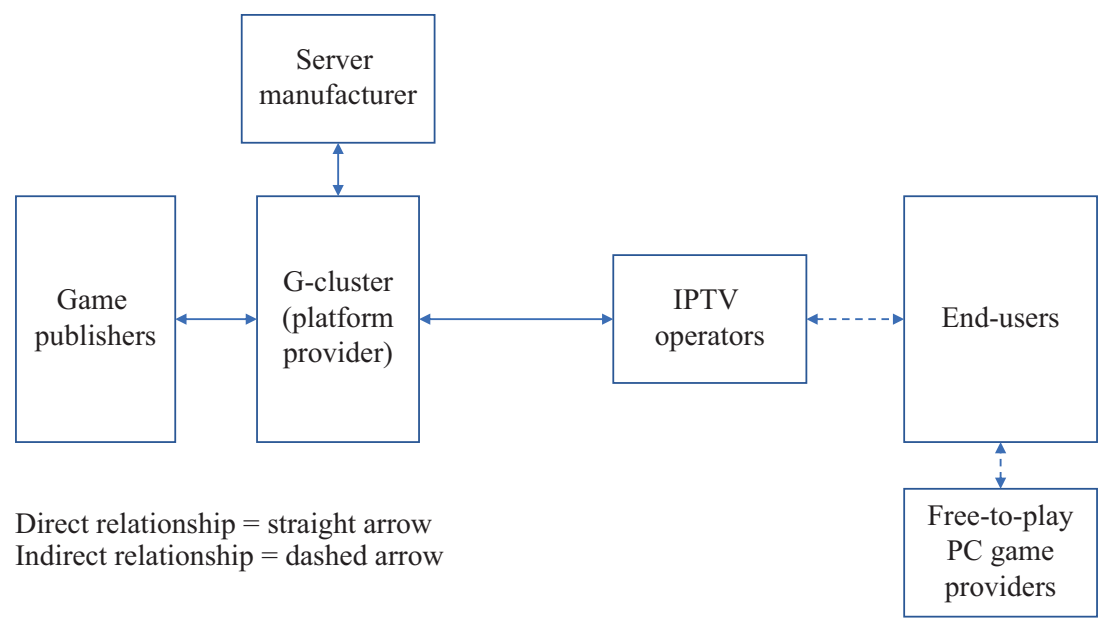

Fig. 6.2 The partner network in 2010 
games, G-cluster focused solely on Internet Protocol Television (IPTV) networks and users and removed the PC market from the network. In addition, the operators had increased their IPTV offering remarkably, and there was ongoing growth in the market as IPTV connections became more reliable.

G-cluster also developed its product further, making it a ready-made service for operators. For instance, G-cluster developed their own billing system and a user interface (menu) that players used to select games from the G-cluster virtual games store. By including these features, G-cluster became less dependent on other firms and strengthened their position in the partner network.

In 2010, G-cluster established a relationship with a large and wellknown server manufacturer that provided cloud technologies for telecom operators. This relationship provided mutual benefits for both firms. The main point of this partnership was mutual value. For G-cluster, the cooperation brought in a more reliable and influential partner, one that could market the gaming service further to telecom operators. This reliable partner increased G-cluster's marketing and sale resources considerably. Conversely, by including G-cluster's cloud gaming feature on the server manufacturer's offering, they obtained added value that the manufacturer was able to use when they marketed their servers to operators.

\subsubsection{Equal Power in a Partner Network}

To multihome the service beyond IPTV operators, G-cluster brought their own cloud gaming console to the market in 2015. The console was a small physical device that connected G-cluster's game service to players' TVs without an IPTV subscription. This console made G-cluster's gaming service available through any telecom operator, as the service was no longer tied to IPTV. Another change in the partner network was that G-cluster no longer cooperated with the server manufacturer (Fig. 6.3). In 2015, G-cluster had well-known operators as reference customers and no longer needed the server manufacturer or other third parties to reassure operators about the service. Thus, although the number of actors in the partner network decreased, G-cluster increased their number of critical partners. This change led to a more stable and co-operative network, where power is more equally dispersed among the actors. 


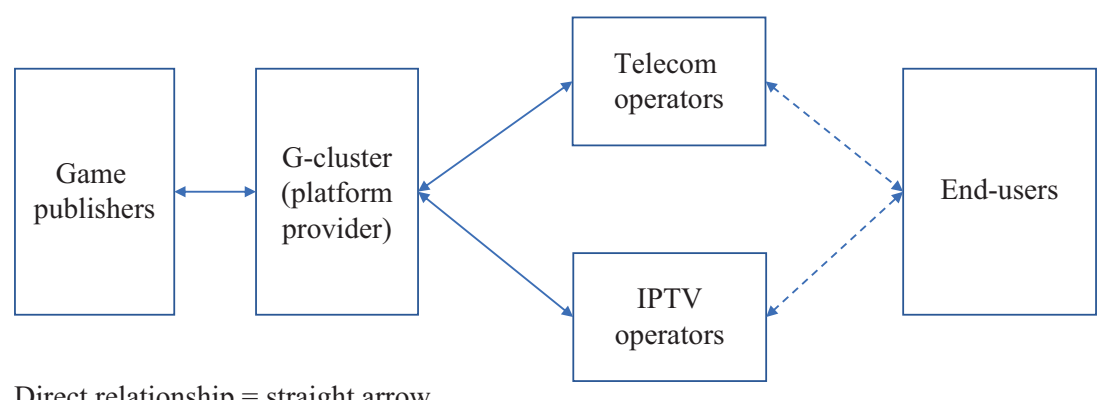

Direct relationship $=$ straight arrow Indirect relationship $=$ dashed arrow

Fig. 6.3 The partner network in 2015

\subsection{ResulTS}

The network's ongoing evolution was evident in the case study. This process is typical for networks, caused by a change in the ecosystem, value creation logic, and the consolidation of relationships between actors. If a firm is to gain a better position in a partner network and market the offering, the firm must cooperate with several kinds of partners. The firm must demonstrate the value of the offering to several partners in the network. This evolution in the network position also affects the power setting. The sources of power and the direct and indirect values between the various actors in each micro-position are shown in Table 6.1.

The direct value was related, in addition to monetary value, to the critical resources that $\mathrm{G}$-cluster needed to commercialise its service. The direct value can be divided into resources enabling the service (provided by game studios and telecom operators) and functionalities needed for the product. For the partners that enabled G-cluster's service, G-cluster provided mainly financial benefits as a direct value. Although indirect value was not critical to G-cluster's service, this value provided substantial help in marketing and networking. Indirect value worked similarly: G-cluster gained resources for marketing and networking, and its partners gained a new feature for their services, one that the partners were able to use in their marketing. 


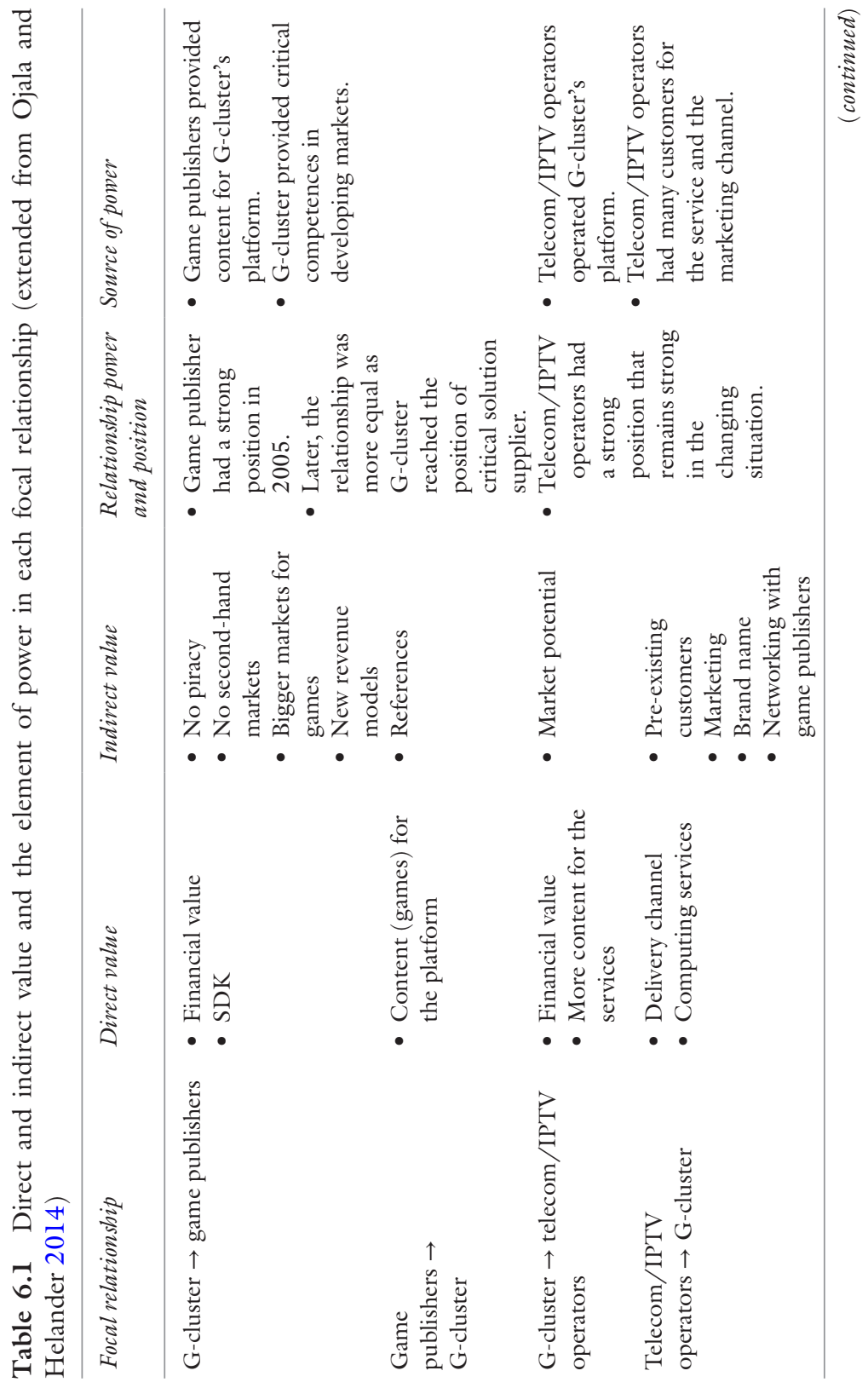




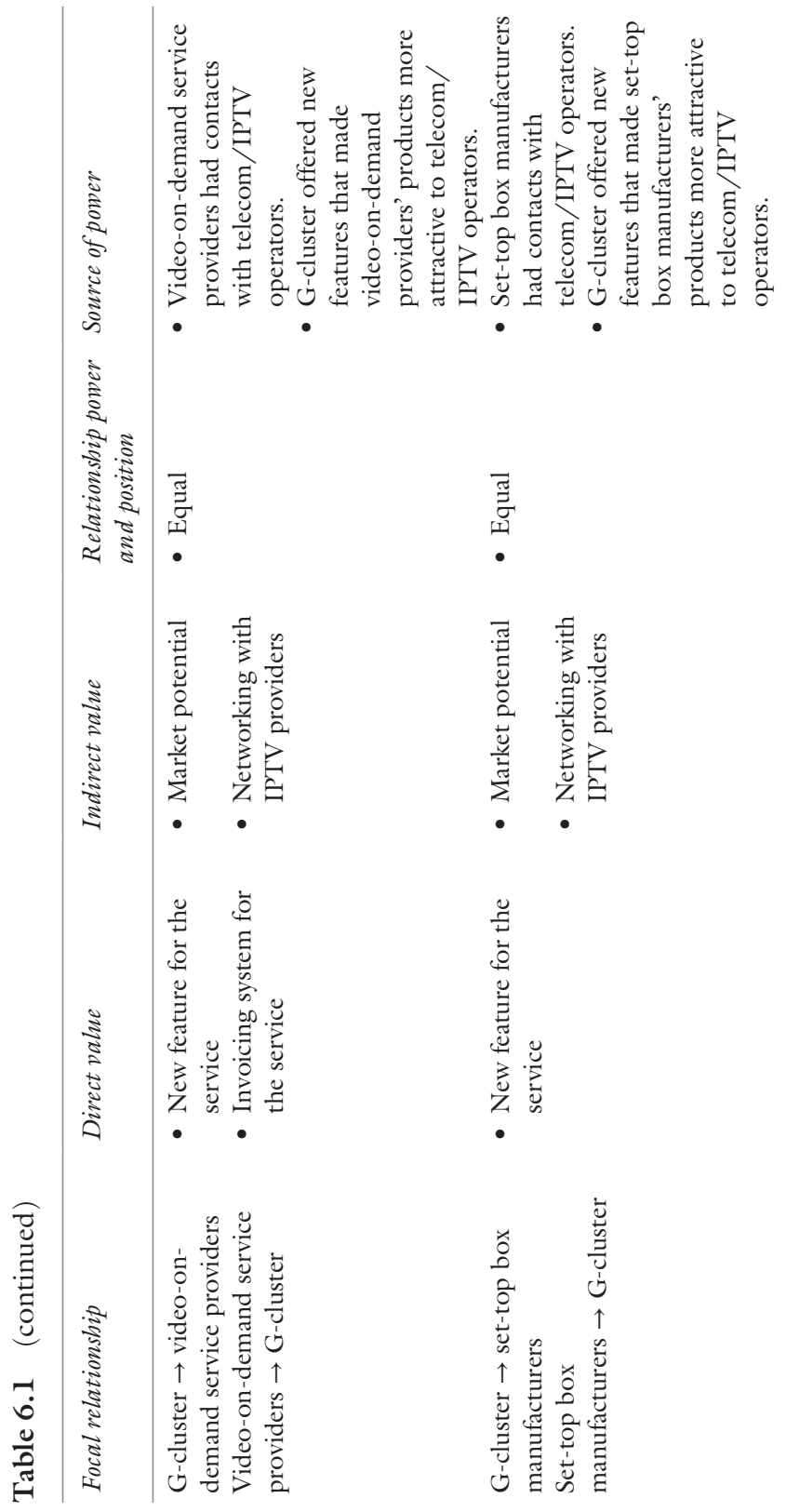



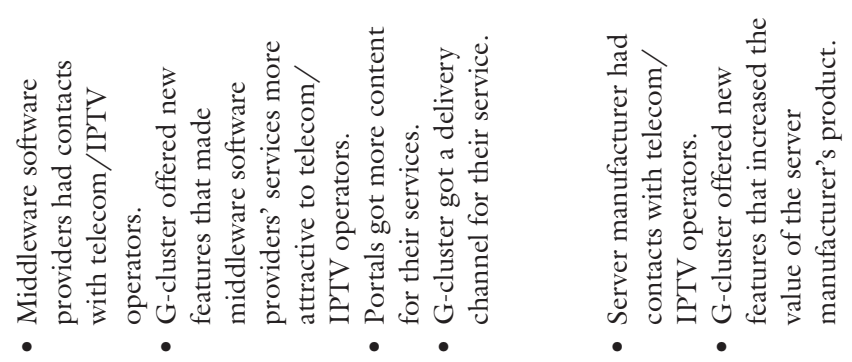

疋
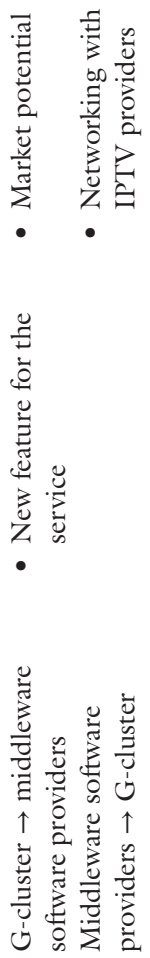

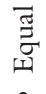

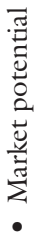
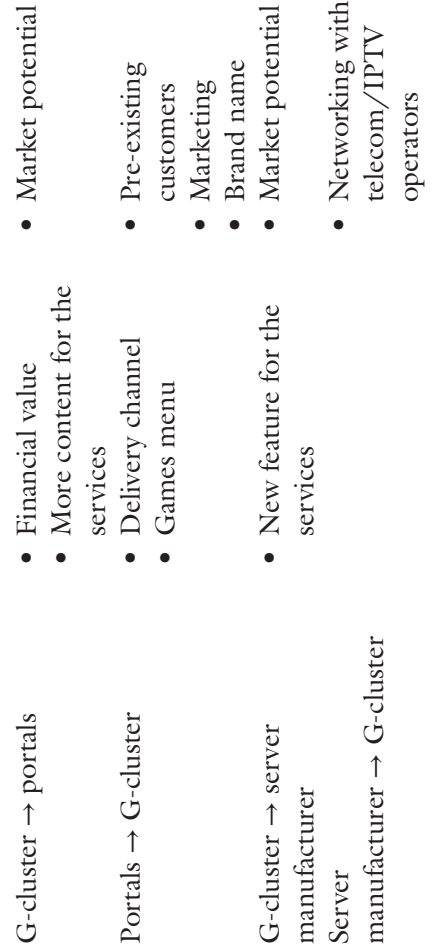
As can be observed from Figs. 6.1, 6.2, 6.3, the partner network evolved from a complex structure involving several actors (in 2005) to a simple network structure that included only the most critical partners (in 2015). Easton (1992) observed that the more the independence of a firm increases, the less fragmented its network becomes. In the G-cluster case, the number of partners in the network decreased over time, but the number of content and telecom operators increased. The firm's network evolved through the following steps. First, the platform provider networked with all possible actors operating within the different layers of the multilayered platform architecture (Yoo et al. 2010) that could benefit from the platform to achieve market visibility. Second, after getting more visibility in the ecosystem, the firm focused on the most powerful actors within the content layer (game studios) and network layer (telecom operators), and developed deeper relationships with them. These actions increased the platform provider's position in the partner network and made it more concentrated.

Power is increased when the focal actor has more alternatives to choose from, and the power position relates to the size of the firm. In the beginning, the telecom operators and game publishers were big companies that had many content and current technology suppliers from which to choose. However, as the technological landscape changed to favour G-cluster's solution and competences, G-cluster achieved a stronger position in the network and became the critical supplier. Critical competences and technological changes in the market acted as the trigger for changes in the network structure and the power positions. Thus, a link between value creation capability and the power position was visible through G-cluster's competences. The direct financial value and the indirect value that G-cluster provides to game publishers and telecom operators exceeded the competitors' value creation capability and led to closer co-operation.

\subsection{Conclusion}

This chapter contributes understanding of digital ecosystems in several ways. First, the chapter incorporated network theory (Johanson and Mattsson 1988), management studies related to organisational power 
(Astley and Sachdeva 1984; Mintzberg 1978), and literature on value creation (Walter et al. 2001). The chapter conceptualised the value creation and evolution of the partner network in the contemporary context of digital ecosystems. Specifically, the chapter provides an in-depth view of how a platform provider can create value with other actors in the network and how the value can be used to form a good network position and power symmetry in the market.

Second, this chapter provides detailed insights into how and why a network changed over 10 years. This is important in developing a realistic view of value creation (Walter et al. 2001) and network development. As Halinen and Törnroos (2005) noted, over time networks change in relation to the problems that they aim to solve and, in this way, to the value they aim to create. When situations change, new kinds of actors may be needed in network cooperation, and this will lead to a change in the network structure.

Third, this chapter provides detailed knowledge on the range of direct and indirect value that network actors create for each other and finally, for the end customer. In addition, the chapter sheds light on the interesting relation between value creation capability and power. Monetary and non-monetary value creation capabilities are needed to ensure the development of a stronger network position and to balance the asymmetric power setting that the larger firm may have in the relationship. Thus, through critical competence development that leads to increased value creation capability, even a small actor may enhance its network position.

\section{REFERENCES}

Adner, Ron. 2012. The Wide Lens: What Successful Innovators See That Others Miss. Penguin.

Allee, Verna. 2000. Reconfiguring the Value Network. Journal of Business Strategy 21 (4): 36-39. https://doi.org/10.1108/eb040103.

Astley, W. Graham, and Paramjit S. Sachdeva. 1984. Structural Sources of Intraorganizational: Power: A Theoretical Synthesis. Academy of Management Review 9 (1): 104-113. 
Baber, William W., Arto Ojala, and Ricardo Martínez. 2019. Transition to Digital Distribution Platforms and Business Model Evolution. 52nd Hawaii International Conference on System Sciences. http://scholarspace.manoa.hawaii.edu/ handle/10125/59937.

Easton, Geoffrey. 1992. Industrial Networks: A Review. In Industrial Networks: A New View of Reality, 3-27. London and New York: Routledge.

Edmondson, Amy C., and Stacy E. Mcmanus. 2007. Methodological Fit in Management Field Research. Academy of Management Review 32 (4): 1155-1179. https://doi.org/10.5465/AMR.2007.26586086.

Eisenhardt, K.M. 1989. Building Theories from Case Study Research. Academy of Management Review 14 (4): 532-550.

Eisenhardt, K.M., and M.E. Graebner. 2007. Theory Building from Cases: Opportunities and Challenges. Academy of Management Journal 50 (1): 25.

Eisenmann, Thomas, Geoffrey Parker, and Marshall W. Van Alstyne. 2006. Strategies for Two-Sided Markets. Harvard Business Review 84 (10): 92-101.

Ford, David, and Michael Redwood. 2005. Making Sense of Network Dynamics Through Network Pictures: A Longitudinal Case Study. Industrial Marketing Management 34 (7): 648-657. https://doi.org/10.1016/j. indmarman.2005.05.008.

Håkansson, Håkan, and Ivan Snehota. 1989. No Business is an Island: The Network Concept of Business Strategy. Scandinavian Journal of Management 5 (3): 187-200. https://doi.org/10.1016/0956-5221(89)90026-2.

Halinen, Aino, and Jan-Åke Törnroos. 2005. Using Case Methods in the Study of Contemporary Business Networks. Journal of Business Research 58 (9): 1285-1297.

Johanson, J., and L.G. Mattsson. 1988. Internationalisation in Industrial Systems: A Network Approach. In Strategies in Global Competition, 287-314. London: Croom Helm.

Koch, Thorsten, and Josef Windsperger. 2017. Seeing Through the Network: Competitive Advantage in the Digital Economy. Journal of Organization Design 6 (1): 6.

Lapierre, Jozée. 2000. 'Customer-Perceived Value in Industrial Contexts. Journal of Business \& Industrial Marketing 15 (2/3): 122-145. https://doi. org/10.1108/08858620010316831.

Lee, Robin S. 2012. Home Videogame Platforms. In The Oxford Handbook of the Digital Economy, 83-107. Oxford: Oxford University Press.

McIntyre, David P., and Arati Srinivasan. 2017. Networks, Platforms, and Strategy: Emerging Views and next Steps. Strategic Management Journal 38 (1): 141-160. https://doi.org/10.1002/smj.2596. 
Miles, Matthew B., and A. Michael Huberman. 1994. Qualitative Data Analysis: An Expanded Sourcebook. SAGE.

Mintzberg, Henry. 1978. Patterns in Strategy Formation. Management Science 24 (9): 934-948.

Ojala, Arto. 2016. Business Models and Opportunity Creation: How IT Entrepreneurs Create and Develop Business Models under Uncertainty. Information Systems Journal 26 (5): 451-476. https://doi.org/10.1111/ isj. 12078 .

Ojala, Arto, and Nina Helander. 2014. Value Creation and Evolution of a Value Network: A Longitudinal Case Study on a Platform-as-a-Service Provider. 2014 47th Hawaii International Conference on System Sciences, 975-984. https:// doi.org/10.1109/HICSS.2014.128.

Ojala, Arto, and Kalle Lyytinen. 2018. Competition Logics During Digital Platform Evolution. 51st Hawaii International Conference on System Sciences. http:// scholarspace.manoa.hawaii.edu/handle/10125/50017.

Ojala, Arto, and Pasi Tyrväinen. 2011a. Value Networks in Cloud Computing. Journal of Business Strategy 32 (6): 40-49. https://doi. org/10.1108/02756661111180122.

- 2011b. Developing Cloud Business Models: A Case Study on Cloud Gaming. IEEE Software 28 (4): 42-47. https://doi.org/10.1109/MS.2011.51.

Ojala, Arto, Natasha Evers, and Alex Rialp. 2018. Extending the International New Venture Phenomenon to Digital Platform Providers: A Longitudinal Case Study. Journal of World Business 53 (5): 725-739. https://doi.org/10.1016/j. jwb.2018.05.001.

Porter, Michael E. 1985. Competitive Advantage: Creating and Sustaining Superior Performance. New York: Free Press.

Tiwana, Amrit. 2013. Platform Ecosystems: Aligning Architecture, Governance, and Strategy. Newnes.

Turnbull, Peter W., and Jean-Paul Valla. 1986. Strategic Planning in Industrial Marketing: An Interaction Approach. European Journal of Marketing 20 (7): 5-20. https://doi.org/10.1108/EUM0000000004652.

Ulrich, Karl. 1995. The Role of Product Architecture in the Manufacturing Firm. Research Policy 24 (3): 419-440. https://doi.org/10.1016/00487333(94)00775-3.

Walter, Achim, Thomas Ritter, and Hans Gemünden. 2001. Value Creation in Buyer-Seller Relationships: Theoretical Considerations and Empirical Results from a Supplier's Perspective. Industrial Marketing Management 30 (4): 365-377. https://doi.org/10.1016/S0019-8501(01)00156-0. 
Yoo, Youngjin. 2010. Computing in Everyday Life: A Call for Research on Experiential Computing. MIS Quarterly 34 (2): 213-231.

Yoo, Youngjin, Ola Henfridsson, and Kalle Lyytinen. 2010. The New Organizing Logic of Digital Innovation: An Agenda for Information Systems Research. Information Systems Research 21 (4): 724-735. https://doi.org/10.1287/ isre.1100.0322.

Open Access This chapter is licensed under the terms of the Creative Commons Attribution 4.0 International License (http://creativecommons.org/licenses/ by $/ 4.0 /$ ), which permits use, sharing, adaptation, distribution and reproduction in any medium or format, as long as you give appropriate credit to the original author(s) and the source, provide a link to the Creative Commons licence and indicate if changes were made.

The images or other third party material in this chapter are included in the chapter's Creative Commons licence, unless indicated otherwise in a credit line to the material. If material is not included in the chapter's Creative Commons licence and your intended use is not permitted by statutory regulation or exceeds the permitted use, you will need to obtain permission directly from the copyright holder.

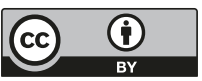

